\title{
Putting Multiliteracies Into Practice: Digital Storytelling for Multilingual Adolescents in a Summer Program
}

\author{
Tuba Angay-Crowder, Jayoung Choi, and Youngjoo Yi
}

In this article we demonstrate how we created a context in which digital storytelling was designed and implemented to teach multilingual middle school students in the summer program sponsored by a local nonprofit organization, the Latin American Association, in a city in the southeastern United States. While implementing the notion of multiliteracies (New London Group, 1996) in the Digital Storytelling classroom, we designed tasks and activities that were aligned with the four components of a multiliteracies pedagogy (i.e., situated practice, overt instruction, critical framing, and transformative practice) in order to engage the students in exploring their multiple literacies and identities by using multiple semiotic modes and resources (e.g., texts, images, and sounds). Our digital storytelling lessons show that multiliteracies practices can be a powerful venue for second-language learners and teachers. We further discuss how multiliteracies practices like digital storytelling can be adapted to other educational contexts.

Dans cet article, nous expliquons la conception et la mise en cuvre d'une narration numérique pour enseigner à des élèves plurilingues à l'élémentaire dans le cadre d'un programme d'été parrainé par un organisme local à but non-lucratif, la Latin American Association, dans une ville du sud-est des États-Unis. Pendant la mise en cuvre de la notion de littératies multiples (New London Group, 1996), nous avons conçu des tâches et des activités conformes aux quatre composantes d'une pédagogie axée sur les littératies multiples (c.-à-d., une pratique localisée, une pédagogie ouverte, un encadrement critique et une pratique transformative) de sorte à engager les élèves dans l'exploration de leurs littératies et leurs identités multiples par l'emploi d'une diversité de modes sémiotiques et de ressources (par ex. textes, images, sons). Nos leçons basées sur la narration numérique démontrent que les pratiques axées sur les littératies multiples peuvent constituer de puissants outils pour les apprenants et les enseignants en langue seconde. Nous terminons par une discussion des possibilités d'adapter les pratiques axées sur les littératies multiples, comme la narration numérique, à d'autres contextes pédagogiques. 
In this article we demonstrate how we applied the theoretical concept of multiliteracies to a pedagogical practice. We describe how we, three volunteer teachers from a university, engaged 12 adolescent multilingual students in the multiliteracies practice of digital storytelling (i.e., multimedia composing that consists of texts, images, and sounds to tell stories) during a summer program sponsored by the Latin American Association (LAA) in a city in the southeastern United States. Each summer, teacher candidates in our English to Speakers of Other Languages (ESOL) teacher education program offer individual tutoring to students at the LAA. In summer 2012, university faculty and the LAA staff members met to discuss goals to accomplish in our partnership in general and in tutoring in particular. During the meeting, the LAA staff asked us to make sure that our teacher candidates emphasized several critical issues during tutoring such as the importance of first language (L1) or heritage language development, positive identity construction, and 21st-century literacies development. We, two faculty members and a doctoral student, volunteered to design and teach a class in which these critical issues could be discussed with multilingual adolescent students, and the LAA staff members allowed us to design a class that could be part of their summer program. We set out to design the Digital Storytelling Class in order: (a) to examine how a theoretical framework (i.e., multiliteracies) could be translated into teaching multilingual adolescents; and (b) to create a context in which students could explore their multiple literacies and identities using multiple semiotic modes and resources (e.g., visuals, sound, gesture, gaze, and spatial concepts). In the following sections, we explain the theoretical framework that we drew on for designing and conducting our multiliteracies curriculum (i.e., digital storytelling lessons), followed by a detailed description of each session in which students engaged in digital storytelling practice. In the conclusion, we discuss how our pedagogical approach can be adapted to other ESL/EFL settings.

\section{Multiliteracies and Digital Storytelling}

In our work with adolescent multilingual students in the summer program, we drew on the theoretical framework of multiliteracies, which was initially proposed by the New London Group (NLG, 1996). The term multiliteracies was coined to address "the multiplicity of communications channels and media, and the increasing saliency of cultural and linguistic diversity" (p. 63). NLG claims that meanings are constructed through multiple representational and communicational modes and resources and further calls for the inclusion of multiple literacies and modes for making meaning. In addition, NLG advocates developing a theory of pedagogy that integrates four components: (a) situated practice; (b) overt instruction; (c) critical framing; and (d) transformed practice. These components formed the theoretical foundation for our digital storytelling curriculum, and here we briefly explain these components. 
Situated practice is an "immersion in meaningful practices within a community of learners who are capable of playing multiple and different roles based on their background and experiences" (NLG, 1996, p. 85). Through situated practice, communities of learners are guided as "masters of practice" (p. 84). Overt instruction does not imply direct drills or rote memorization, but includes "active interventions on the part of the teacher and other experts that scaffold learning activities ... that allow the learner to gain explicit information" (p. 86). It helps students develop "conscious awareness and control over what is being learned" (p. 86) and use an explicit metalanguage that describes various processes and elements that contribute to meaning. Collaborative efforts between teacher and student are critical to overt instruction. Despite the importance of situated practice and overt instruction in literacy pedagogy, they are insufficient to help students develop critical or cultural understanding of language and literacy; thus two other components (critical framing and transformed practice) must be supplemented for an efficacious pedagogy. Through critical framing, which involves both cognitive and social dimensions of literacy pedagogy, students step back from what they have learned, critique their learning, and extend and apply their learning in new contexts. Transformed practice involves students' transfer, reformulation, and redesign of existing texts and meaning-making practice from one context to another. A certain degree of tension exists when students engage in transformed practice, especially when they juxtapose and integrate diverse discourses and remake their own realities or discourses to suit their needs and purposes. Importantly, these four components are often interrelated, and an integration of the four components is necessary for effective literacy teaching and learning (Kasper, 2000).

While considering the integration of these four components into our curriculum, we selected one multiliteracies practice, digital storytelling, for our summer class. Research shows that digital storytelling can provide students with rich opportunities: (a) to explore, express, and reflect themselves (Skinner \& Hagood, 2008); (b) to enhance critical thinking (Ohler, 2005); (c) to foster academic achievement (Yang \& Wu, 2012); and (d) to build leadership skills (Guajardo et al., 2011). For multilingual adolescent students, digital storytelling can provide an opportunity to design multimodal narratives that represent and reflect on their sociocultural identities and their lives. For example, Skinner and Hagood's study about Chinese immigrant teenager Allie Feng showed that creating her digital story (e.g., aptly combining personal photos, music, and narrative writing) provided her with an important opportunity to reflect on her multiple identities across China and the US. Perhaps more important, digital storytelling was a powerful venue for helping Allie to use her L2 English in order to make sense of her life as "inclusive of interesting cultural identities and literacies" (p. 29). As Skinner and Hagood noted, exploring and reflecting on the relationship between students' 
cultural identities and literacies through digital storytelling can further promote the "development of empowering critical literacies" (p. 29) for Englishlanguage learners. In this sense, digital storytelling can be an intriguing practice for many multilingual adolescent students to negotiate their multiple literacies and positive cultural identity.

\section{Context: Digital Storytelling Class in the Summer Program}

The digital storytelling class took place in a traditional classroom and a computer lab for 90 minutes twice a week during a four-week summer program. Of 60 middle school students who participated in the summer program, 12 students in grades 7 and 8 were carefully selected for our digital storytelling class by the director of Youth and Volunteer Initiatives at the LAA. The director selected students who would be interested in producing digital stories. All the students were children of immigrants and spoke a language other than English at home: 10 came from Spanish-speaking homes, one whose parents came from Bangladesh had limited proficiency in Bengali, and one who emigrated from the Philippines had advanced proficiency in Tagalog. These students were encouraged to tap into their rich linguistic and cultural knowledge for their digital stories.

\section{Designing and Conducting the Digital Storytelling Class}

We designed and conducted a total of seven sessions to engage 12 students with digital storytelling practice. We prepared each lesson together and engaged in debriefing discussions after each lesson and planned for the next lesson. Notably, almost all the students' activities for digital storytelling involved the four components of multiliteracies.

\section{Building a Foundation for Digital Storytelling: Week 1} (Sessions 1 and 2)

During the first week, we employed situated practice and overt instruction to teach the students "what digital storytelling is," "how it can be created," and "why students need to consider their purpose and audience in digital storytelling." We started our first session by introducing ourselves and conducting a needs analysis in which students reported their preferred out-ofschool activities, their use of technologies, and their L1 proficiency. The result of the needs analysis and class discussions about their interests gave us some insights into their strengths, on which we could capitalize in class, and they further helped us design and modify our subsequent lessons.

The students brainstormed potential topics for their digital stories based on initial conversations about their interests. They worked individually or in pairs on various topics of their choice ranging from sociopolitical issues (e.g., immigration policies and environmental issues) and their heritage (e.g., 
introduction to their home country) to personal interests (e.g., Six Flags theme parks, video games, and sports). In this situated practice, we challenged the students to reflect critically on their topic selection and to reframe their choices while raising questions that helped them think harder about whether their topics could serve their purposes and entertain their audience.

We also offered overt instruction that aimed to scaffold learning activities and give them explicit information about the nature of digital storytelling. First, drawing on Bull and Kajder (2004) and Robin (2008), we made and presented a PowerPoint presentation about a definition of digital storytelling, as well as 10 key steps and strategies to consider for a great digital story: (a) find your story; (b) map your story; (c) capture your audience's attention right away and keep it; (d) tell your story from your unique point of view; (e) use fresh and vivid language; (f) integrate emotions-yours and audience's; $(\mathrm{g})$ use your own voice in the script and in the audio; (h) choose your images and sounds carefully; (i) be as brief as you can be; and (j) make sure your story has a good rhythm. We then briefly demonstrated how to download and use the computer software Photostory 3 and showed some examples of digital stories, followed by a critique of each.

Keeping these key characteristics of digital storytelling in mind, students first engaged in free writing (e.g., one or two paragraphs about their topic). They then filled out a storyboard template based on their initial free writing while carefully considering multiple modes (e.g., narration, images, audio) for each slide so that they could express their meaning effectively and creatively in their digital stories. Importantly, students' engagement with restructuring text-based free writing into a storyboard, which required them to formulate various modes of expression, was a transforming practice. In this transformation process, each of us circulated around the classroom to help individual students develop critical framing. In other words, we challenged students to critique their initial selections of images and sounds for their digital stories in order to achieve the specific meanings that they intended to deliver. Thus the students stepped away from what was initially familiar to them and reflected critically on the aptness of multiple modes to their central message in the digital story.

\section{Writing Narratives for Digital Storytelling: Week 2 (Sessions 3 and 4)}

The second week centered on strengthening the students' narratives for digital stories. We sensed that some students seemed to lose sight of the importance of constructing a solid narrative and paid more attention to locating other nonlinguistic resources (e.g., music or pictures) on the Internet. Their initial narratives lacked a clear sense of purpose and audience. So we implemented a series of situated writing activities in class such as responding to writing prompts, outlining a narrative, composing a structured essay based on their outlines, and participating with us in individual writing conferences. 
More specifically, we asked students to respond to two writing prompts: "What message do you want to convey to your audience?" and "Please share reasons for selecting your topic and the potential audience for your story." By sharing their responses to these prompts with the class, students seemed to develop a clear sense of purpose and audience for their digital stories. They also engaged in outlining their narratives to generate more ideas and better organize their narratives, and then composed more structured and developed (e.g., three-paragraph) narratives. While engaging in these writing activities, each student or group had a writing conference (which was overt instruction) with each of us. During the individual conference, we often asked a student or a group to elaborate on their topic and explicitly corrected or suggested better word choice, sentence structure, and spelling. In addition, we encouraged them to incorporate code-switching in their narratives (e.g., using their heritage or first language), which seemed to help them "highlight creativity and criticality" (Wei, 2011, p. 370) in their digital stories. In fact, the code-switching practice transformed the writing conventions for these students, who were accustomed to writing for school only in English. Clearly, students transformed their initial drafts into embellished revisions of their narratives while engaging in situated practice, overt instruction, critical framing, and transformed practice.

Finally, as part of providing overt instruction and creating an apprenticelike environment, we created a virtual space (wikispace) where we made available additional resources about digital storytelling and where students shared information about their digital stories. Participating in this budding community facilitated the process of seeking diverse perspectives on their topics.

\section{Orchestrating Text, Image, and Sound: Week 3 (Sessions 5 and 6)}

As the students had almost finished their narratives, the primary tasks during the third week involved selecting appropriate images and sounds, modifying linguistic text, and recording a narration; more important, they had to orchestrate multiple modes (e.g., text, image, and sound) to create effective and powerful messages for their audience. During Week 3, we wished to lead the students to reflect critically on their process of composing from writing print-based narratives to selecting and orchestrating both linguistic and nonlinguistic modes for a digital story so that they could transform or expand their conception of writing.

Considering the significance and difficulty of aptly adapting nonlinguistic modes to digital stories, we offered overt instruction (i.e., two PowerPoint presentations) through which the students learned how to select and orchestrate various nonlinguistic, semiotic modes in digital stories. One presentation focused mainly on how to use the software Photostory 3, to which the students had been introduced earlier. This time, we explained each step in creating a digital story with the software (e.g., where to type narratives, how to upload 
sound files, how and where to insert text). By doing this, we wished to ensure that technological difficulties would not prevent the students from developing a digital story in a creative and sophisticated manner.

In another presentation, we facilitated students' thinking about differences and similarities between print-based (e.g., a traditional five-paragraph essay) and digital multimodal practices (e.g., digital storytelling) so that they could reach a deeper understanding of the importance of a deliberate selection of nonlinguistic modes for digital multimodal practices. Further, students shared their personal reflections or experiences about instances where images or music delivered a more powerful message than did text. Keeping these discussions in mind, students not only paid attention to how each nonlinguistic mode contributed to the overall meaning, but they also considered how the orchestration of text-image-sound best fitted their message. We also encouraged students to help each other to make smooth and logical transitions between scenes and to decide on the pace of their narration and the tone of their voice in the stories.

While students were building their projects in the computer lab, we circulated around the classroom and asked them questions that challenged their selection of nonlinguistic modes such as "Why are you using this particular image and tone of voice here?" and "What effect does this image or sound have on your overall meaning?" By discussing these questions, we hoped that the students would raise their awareness of the process of the project and enhance their deliberate selection of multiple modes and resources. Of importance here is that we provided overt instruction and engaged the students in critical framing by providing them with opportunities to distance themselves from their initial choices of multiple modes, critique them for aptness, and modify and improve their use of multiple modes and resources.

Another notable aspect of the process of creating a digital story during Week 3 was that some students consulted with their parents and other adults in their local community about the accuracy of information in their digital stories, especially in narratives about their heritage country or culture (e.g., introduction to Guatemala or the Philippines) or some critical and difficult social issue (i.e., anti-immigration policies). We found that these adolescent multilingual students capitalized on their home/community-based languages, discourses, and knowledge for digital storytelling, which is more often a school-based academic activity. Importantly, some of them seemed to negotiate tensions between school-based and home/community-based knowledge and practices. For example, a few students who were accustomed to school discourse and practice did not include any language other than English (e.g., Spanish) in their narratives despite our explicit request for them to use multiple languages. Similarly, one student initially refused to include knowledge about her heritage country and culture in her project because she thought that they would be non-legitimate or inappropriate topics for a 
school project. However, through much reflection and discussions, many students came to design their own discourse and reality while drawing on both school and home/community worlds. Students' insertion of narrative or text in their first or heritage language and their consultations about their projects with parents and other adults in their communities were indications of transformed practice at work. From this transformed practice, we saw the value of digital storytelling in that it enabled classroom teachers to engage in mediated communication with parents to address topics or issues (e.g., heritage culture or social issues) that are raised by students.

\section{Reflecting, Sharing, and Celebrating: Week 4 (Session 7)}

During the last week, students celebrated their final productions by reflecting on the whole process of creating digital stories and sharing their projects with an audience. Before the students' presentations in class, we provided overt instruction in which we first showed an example of a digital story on YouTube and then modeled "how to raise questions" for facilitating further reflections on the process, product, and delivery of digital stories. For example, we asked questions such as "What was it like to make the project?" "What did you learn from doing it?" "Whom did you have in mind as audience for your work?" and "What and how would you have done differently?" Immediately afterward, each student took a turn playing his or her digital storytelling project on a large screen for the class. Overall, students showed great interest and enthusiasm in their peers' productions, especially those on topics with which they were not familiar. After sharing and discussing the lessons learned from producing a digital story with the class, we taught them how to upload projects to YouTube to reach a wider audience. The idea of sharing their projects with a YouTube audience excited these students very much. Based on class discussions, we collectively selected two projects for showing in the Parents' Night event at the LAA. In the end, digital stories turned into a powerful reflection tool through which students made sense of their experiences and sought meaning from their lives.

\section{Conclusion}

Engaging students in multiliteracies as reported here gives us some valuable insights into what counts as literacy learning and teaching and how we reframe literacy pedagogy in our 21st-century classrooms. While they were producing their digital stories, our students engaged in "assembling, editing, processing, receiving, sending, and working on information and data to transform diverse resources of 'digitalia' ... into new digital resources and multimodal texts with representational meaning and communicative purposes" (Lankshear \& Knobel, 2003, p. 173). Both conventional print-based and computer-based multimodal composing practices seem to help students expand their literacy repertories and means of expression (Hull \& Nelson, 
2005). This type of curriculum can be particularly powerful for multilingual adolescents as it permits them to reflect on and recreate their multilingual and multicultural lives and identities (Skinner \& Hagood, 2008). In addition, it can develop students' leadership skills as they work as a team, set goals, manage time and resources, and construct a positive identity. Despite much success with our curriculum, we felt limited in that most students could not continue to engage in multiliteracies practices after the summer program because of limited technological resources in their homes. We also recognize that our pedagogical approach in our summer program context might not resonate with some ESL classroom teachers who often face constraints with time, resources, and rigid curriculum. Nevertheless, the detailed class tasks that are aligned with the four components in a multiliteracies pedagogy (Kern, 2000; NLG, 1996) in our setting could enhance future pedagogical endeavors in designing and implementing similar multiliteracies curriculum in other educational contexts. For example, ESL or EFL teachers of large classes could create collaborative pair or group digital storytelling projects that are shorter in length and could invite other teachers (e.g., media specialists or content-area teachers) to integrate digital storytelling into a thematic unit as part of an interdisciplinary project. Regardless of the modifications that teachers make in their contexts, providing specific guidance to students throughout the digital storytelling process and creating a collaborative environment in which both students and the teachers learn from one another (Vinogradova, Linville, \& Bickel, 2011) are essential to an efficacious multiliteracies pedagogy.

\section{Acknowledgments}

Weare grateful to students and staff members at the Latin American Association for their cooperation and support and to the anonymous TESL Canada Journal reviewers and the Editor for their insightful and encouraging comments on an earlier version of this article.

\section{The Authors (listed in alphabetical order by family name with equal contribution)}

Tuba Angay-Crowder is a doctoral student in a language and literacy program at Georgia State University. Her research interests include second-language writing and multiliteracies. She is more specifically interested in how teachers can apply academic literacies to improve the content knowledge of the ESL students.

Jayoung Choi is a clinical assistant professor of ESOL/Literacy education in the college of education at GeorgiaStateUniversity. Her researchinterestsincludeadolescentEnglish-languagelearners'(ELLs') literacy practices and their identity negotiation and multimodal literacies taken up and practiced by ELLs and ESOL teachers.

Youngjoo Yiis an associate professor in second- and foreign-languageeducation at the OhioState University. Her researchinterestsincludeadolescentmultilingualstudents' literacy-learning and identityconstruction. Her work has been published in the Journal of Second Language Writing, Journal of Adolescent and Adult Literacy, and Foreign Language Annals. 


\section{References}

Bull, G., \& Kajder, S. (2004). Digital storytelling in the language arts classroom. Learning and Leading with Technology, 32(4), 46-49.

Guajardo, M., Oliver, J.A., Rodriguez, G., Valadez, M.M., Cantu, Y., \& Guajardo, F. (2011). Reframing the praxis of school leadership preparation through digital storytelling. Journal of Research on Leadership Education, 6(5), 145-161.

Hull, G.A., \& Nelson, M.E. (2005). Locating the semiotic power of multimodality. Written Communication, 22(2), 224-261.

Kasper, L.F. (2000). New technologies, new literacies: Focus discipline research and ESL learning communities. Language Learning and Technology, 4(2), 105-128.

Kern, R. (2000). Literacy and language teaching. New York: Oxford University Press.

Lankshear, C., \& Knobel, M. (2003). New literacies: Changing knowledge and classroom learning. Milton Keynes, UK: Open University Press.

New London Group. (1996). A pedagogy of multiliteracies: Designing social futures. Harvard Educational Review, 66, 60-92.

Ohler, J. (2005). The world of digital storytelling. Educational Leadership, 63(4), 44-47.

Robin, B.R. (2008). Digital storytelling: A powerful technology tool for the 21st-century classroom. Theory into Practice, 47, 220-228.

Skinner, E.N., \& Hagood, M.C. (2008). Developing literate identities with English language learners through digital storytelling. The Reading Matrix, 8(2), 12-38.

Vinogradova, P., Linville, H.A., \& Bickel, B. (2011). “Listen to my story and you will know me": Digital stories as student-centered collaborative projects. TESOL Journal, 2, 173-202.

Wei, L. (2011). Multilinguality, multimodality, and multicompetence: Code- and modeswitching by minority ethnic children in complementary schools. Modern Language Journal, 95, 370-384.

Yang, Y.-T.C., \& Wu, W.-C.I. (2012). Digital storytelling for enhancing student academic achievement, critical thinking, and learning motivation: A year-long experimental study. Computers and Education, 59, 339-352. 